\title{
Echocardiographic Abnormalities in Patients with HIV Infection at Komfo Anokye Teaching Hospital, Ghana
}

\author{
Isaac Kofi Owusu ${ }^{1,2^{*}}$ and Bright Oppong ${ }^{2}$ \\ ${ }^{1}$ Department of Medicine, School of Medical Sciences, College of Health Sciences, Nkrumah University of Science and Technology, Kumasi, Ghana \\ ${ }^{2}$ Department of Medicine, Komfo Anokye Teaching Hospital, Kumasi, Ghana
}

"Corresponding author: Isaac Kofi Owusu, Department of Medicine, School of Medical Sciences, College of Health Sciences, Kwame Nkrumah University of Science and Technology, Kumasi, Ghana, Tel: +233 2445657 02, +233 2064200 59; E-mail: ikeowusu@yahoo.com

Rec date: Dec 24, 2013, Acc date: Feb 17, 2014, Pub date: Feb 25, 2014

Copyright: (c) 2014 Owusu, et al. This is an open-access article distributed under the terms of the Creative Commons Attribution License, which permits unrestricted use, distribution, and reproduction in any medium, provided the original author and source are credited.

\begin{abstract}
Human immunodeficiency virus (HIV) infection is a global public health issue and a major problem in subSaharan Africa. This study was a descriptive cross-sectional study designed to determine the prevalence of cardiovascular abnormalities in HIV positive patients using echocardiography. The study was carried out at the Komfo Anokye Teaching Hospital (KATH), Kumasi, Ghana. Treatment naïve HIV positive patients aged between 16 and 82 years were recruited from the HIV clinic using simple random sampling. Disease history documentation, physical examination and trans-thoracic echocardiography were performed on all study participants. Two hundred (200) patients were studied. They were aged between 16 and 82 years with the mean age $( \pm$ SD) of $40.6( \pm 10.5)$ years. There were more females $(74.5 \% ; n=149)$ than males $(25.5 \% ; n=51)$. The overall prevalence of cardiovascular abnormalities was $55.5 \%(n=111)$. The cardiovascular abnormalities seen were pulmonary hypertension $(38.50 \%)$, dilated cardiomyopathy $(34 \%)$, pericardial effusion $(23.50 \%)$, left ventricular systolic dysfunction (17.50 \%) and left ventricular diastolic dysfunction (9.50\%). Moderate pericardial effusion was seen in $9.5 \%$ of the patients whilst minimal pericardial effusion was seen in $14 \%$. No patient was seen with severe pericardial effusion. For the patients with pulmonary hypertension, the mean ( \pm SD) right ventricular systolic pressure (RVSP) was $51.5( \pm 7.8) \mathrm{mmHg}$, (range; $40-70 \mathrm{mmHg}$ ). In conclusion, there was a high prevalence of cardiovascular abnormalities among adult HIV positive patients attending the HIV clinic at KATH, Kumasi, Ghana. The main cardiovascular abnormalities were pulmonary hypertension, dilated cardiomyopathy and pericardial effusion.
\end{abstract}

Keywords: HIV infection; Cardiovascular abnormality; Echocardiography; Ghana; Tertiary hospital

\section{Introduction}

Human immunodeficiency virus (HIV) infection is a global public health issue and a major problem in sub-Saharan Africa [1,2]. HIV infection is now the principal cause of death in young adults in many parts of the world, and morbidity and mortality have increased several folds in sub-Saharan Africa where modern health care is unavailable to many [1-4].

HIV disease is characterized by an acquired, irreversible, profound immune-suppression that predisposes patients to multiple opportunistic infections, malignancies, and progressive dysfunction of multiple organ systems $[5,6]$.

HIV infection is frequently associated with cardiac involvement. HIV may affect all layers of the heart; endocardium, myocardium or pericardium $[7,8]$. Heart abnormalities caused by pulmonary disease have also been described [9]. Cardiac involvement may either be due to direct infection, as HIV nucleic acid sequences have been detected in cardiac myocytes, [10] or to opportunistic infections. The exact pathogenesis of the cardiac manifestations remains unclear, but is most likely multifactorial [4,11-13].

Almost any agent that can cause disseminated infection in patients with HIV infection may involve the myocardium, but clinical evidence of cardiac disease is usually overshadowed by manifestations in other organs, primarily the brain and lungs. Thus, the number of patients with HIV infection and cardiac involvement at necropsy greatly exceeds the number with significant cardiac disease during life [14]. Estimates of prevalence of cardiac abnormalities in HIV infection vary widely from $28-73 \%[6,11]$.

HIV-associated cardiomyopathy is an important contributor to morbidity and mortality in HIV-positive patients that can be detected early in many cases and may be treated effectively. Some studies have shown that among patients with dilated cardiomyopathy, HIV is the underlying cause in $4 \%[15,16]$. Dilated cardiomyopathy has also been found by other studies to affect $10-20 \%$ of those with HIV infection, and dilated cardiomyopathy has been shown to account for approximately a third of HIV related deaths [6,7].

Valvular heart disease in HIV positive patients occurs as a bacterial or mycotic endocarditis. Bacterial endocarditis is seen almost exclusively in intravenous drug users where prevalence has been found to range from $6.3-34 \%[17,18]$. Intravenous drug users have frequent bacteraemias owing to the introduction of skin pathogens by unsterile intravenous injection. Vegetations form on the tricuspid and pulmonary valve with resultant pulmonary embolism and septic pulmonary infarction. Staphylococcus aureus is the most common organism followed by Streptococcus pneumoniae and Haemophilus influenzae, although these patients are also at increased risk of Salmonella infection $[19,20]$.

Pericardial disease is a frequent cardiovascular manifestation of patients with HIV infection, and it is often associated with shortened 
survival. The prevalence of pericardial disease at echocardiography has been shown to range from $10-59 \%$ [5], and was $21 \%$ in the largest series of 1139 patients with HIV disease [21]. A report from South Africa, showed that $96 \%$ of HIV positive patients with large pericardial effusions had tuberculous pericarditis [22].

Pulmonary hypertension is a severe life-threatening disease, often affecting younger patients. The connection between HIV infection and the development of pulmonary hypertension is well documented $[23,24]$. The incidence of pulmonary hypertension is high in HIV positive patients compared to the general population [23,24]. The underlying pathology of pulmonary hypertension still remains unclear. Given that the prognosis of HIV infection has been improved by anti-retroviral therapy, severe pulmonary hypertension is becoming a life-limiting factor [25].

The prevalence of cardiovascular abnormalities in HIV positive patients in Kumasi, Ghana is unknown. This study seeks to determine the prevalence of cardiac abnormalities in HIV positive patients using echocardiography.

\section{Materials and Methods}

This study was a descriptive cross-sectional study carried out at the HIV clinic of Komfo Anokye Teaching Hospital (KATH), Kumasi, Ghana between August 2010 and February 2011. Ethical approval was obtained from the appropriate ethical committee.

Treatment naïve HIV positive patients aged between 16 and 82 years were recruited from the HIV clinic using simple random sampling. The patients had no prior history of cardiac disease. All participating patients signed a written informed consent. Patients were excluded if they were taking anti-retroviral treatment, if there was a history of congenital heart disease, or if they did not consent to participate. Disease history documentation and physical examination were performed on all study participants by the study physician.

Transthoracic echocardiography was performed using SONOS 5000 Phillips machine equipped with a $3.5 \mathrm{MHz}$ probe. Patients were examined in the left lateral decubitus position and the procedure followed the joint European Association of Echocardiography and American Society of Echocardiography guidelines [26]. Left ventricular (LV) mass was calculated using an autopsy validated formula by Devereux et al. and indexed to body surface area to determine LV mass index (LVMI) [27]. Left ventricular hypertrophy ( $\mathrm{LVH}$ ) was considered present when LVMI was $>104 \mathrm{~g} / \mathrm{m} 2$ in women and $>116 \mathrm{~g} / \mathrm{m} 2$ in men [27]. LV end-diastolic and systolic volumes were measured using Simpson's biplane method and were used to calculate ejection fraction, stroke volume and cardiac output as currently recommended [27].

Left ventricular systolic dysfunction was considered present when the ejection fraction was $<50 \%$, and left ventricular diastolic dysfunction was defined as the presence of any of the following: E/A ratio $<1$, mitral valve deceleration time $\geq 240 \mathrm{~ms}$, or isovolumic relaxation time $\geq 105 \mathrm{~ms}$; or E/A ratio $>2$ [28]. Dilated cardiomyopathy was defined as the presence of ventricular chamber(s) dilatation and global hypokinesia in the absence of any apparent cause of global dilatation and hypokinesia.

Pericardial effusion was considered present when there was an echo-free space between the visceral and parietal pericardia that persisted throughout the whole cardiac cycle. Effusion was graded as mild when it was $<0.5 \mathrm{~cm}$, moderate when it was 0.5 to $2 \mathrm{~cm}$, and severe when it was $>2 \mathrm{~cm}$ on two-dimensional pictures during diastole.

Pulmonary hypertension was defined as echocardiographically estimated pulmonary arterial systolic pressure $>35 \mathrm{mmHg}$ with or without dilated and/or hypertrophied right ventricle and in the presence of dyspnoea. In the absence of pulmonary stenosis, right ventricular systolic pressure $(\mathrm{RVSP})=$ pulmonary systolic hypertension. Maximal velocity of tricuspid regurgitation (V) was measured, and using the formula below, the right ventricular systolic pressure was determined.

\section{$\mathrm{RVSP}=4 \mathrm{~V} 2+\mathrm{CVP} \mathrm{mmHg}$,}

Where CVP is central venous pressure; which was also estimated as below:

\section{$5 \mathrm{mmHg}=\mathrm{IVC}<2.3 \mathrm{~cm}$ and collapses $>50 \%$ with inspiration \\ $10 \mathrm{mmHg}=\mathrm{IVC}<2.3 \mathrm{~cm}$ and collapses $<50 \%$ with inspiration \\ $15 \mathrm{mmHg}=\mathrm{IVC}>2.3 \mathrm{~cm}$ and collapses $<50 \%$ with inspiration \\ $20 \mathrm{mmHg}=\mathrm{IVC}>2.3 \mathrm{~cm}$ and no respiratory collapse \\ Where IVC is inferior vena cava.}

\section{Statistical analysis}

Sample size for the study was calculated using the following formula: $\mathrm{n}=\mathrm{z}^{2} \mathrm{p} \mathrm{q} / \mathrm{d}^{2}$

Where, $\mathrm{n}=$ sample size, $\mathrm{z}=\mathrm{z}$ score at $95 \%$ confidence interval (1.96), $\mathrm{p}=$ estimated prevalence of HIV infection $(6 \%), q=1-p, d=$ margin of error (0.05).

$$
\mathrm{n}=1.96^{2} \times 0.06 \times 0.94 / 0.05^{2}=87 \text { (minimum sample size). }
$$

Data were entered into a Microsoft Excel (2010) sheet. Data were cleaned and abnormal variable and wrong entry removed or changed. Data were then exported into SPSS 12.0 software for analysis. Descriptive analysis of baseline parameters was provided. Measure of central tendency using mean was calculated, and measure of spread using standard deviation and range were also calculated.

\section{Results}

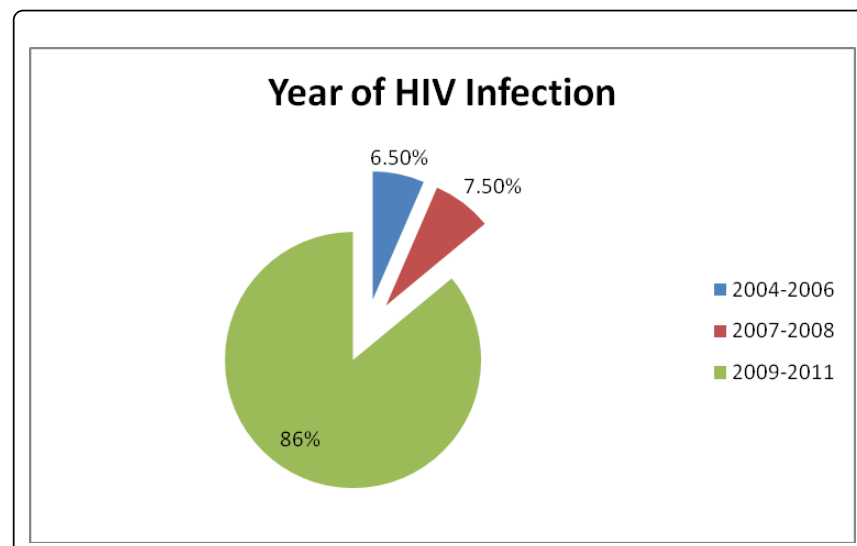

Figure 1: Year of Diagnosis HIV Infection

Two hundred (200) patients were studied. They were aged between 16 and 82 years with the mean age $( \pm$ SD) of $40.6( \pm 10.5)$ years. There 
Citation: Owusu IK, Oppong B (2014) Echocardiographic Abnormalities in Patients with HIV Infection at Komfo Anokye Teaching Hospital,

Page 3 of 5

were more females $(74.5 \%)$ than males (25.5\%). Figure 1 shows year of diagnosis of HIV infection. Majority (86\%) of the patients were diagnosed between 2009 and 2011.

Echocardiogram was abnormal in 111 of the HIV positive patients; giving rise to the overall prevalence of cardiovascular abnormalities among the 200 patients as $55.5 \%$. Figure 2 shows the cardiovascular abnormalities seen in the HIV positive patients. These included: pulmonary hypertension (38.50\%), dilated cardiomyopathy (34\%), pericardial effusion $(23.50 \%)$, left ventricular systolic dysfunction (17.50\%) and left ventricular diastolic dysfunction (9.50\%).

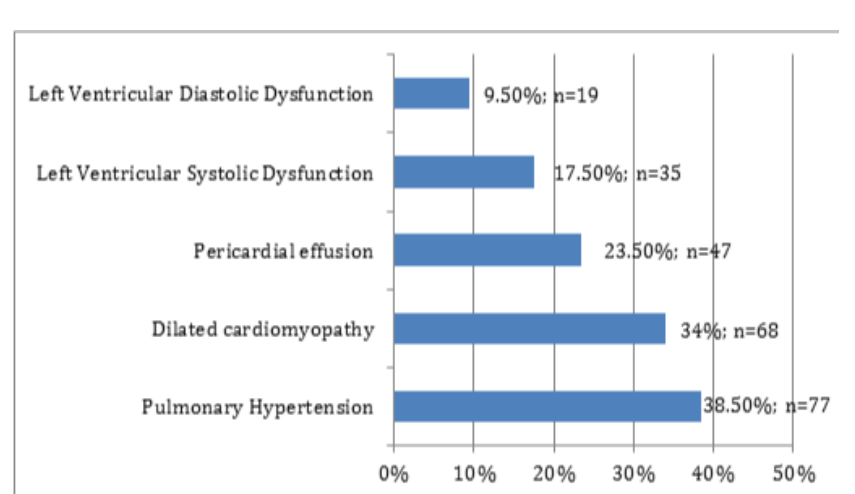

Figure 2: Cardiovascular abnormalities seen in the HIV positive patients

Figure 3 shows the severity of pericardial effusion. Moderate pericardial effusion was seen in $9.5 \%$ of the patients whilst minimal pericardial effusion was seen in $14 \%$. No patient was seen with severe pericardial effusion.

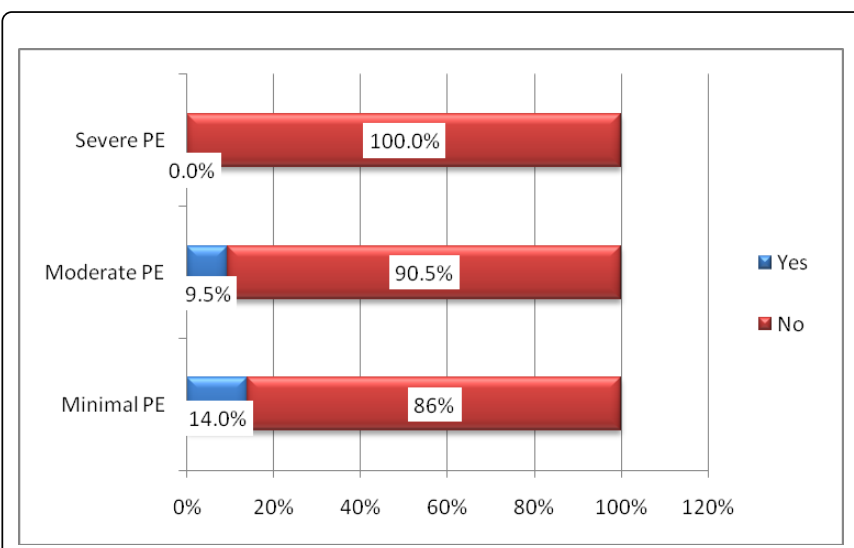

Figure 3: Severity of Pericardial Effusion

\section{PE: Pericardial effusion}

For the patients with pulmonary hypertension, the mean $( \pm S D)$ RVSP was 51.5 ( \pm 7.8$) \mathrm{mmHg}$, (range; 40-70 $\mathrm{mmHg}$ ).

Tables 1 and 2 show echocardiographic characteristics of the HIV positive patients with dilated cardiomyopathy, and those with left ventricular systolic dysfunction, respectively. For the patients with dilated cardiomyopathy, the mean $( \pm \mathrm{SD})$ left ventricular end-diastolic dimension (LVIDd) was 6.35 ( \pm 0.69$)$, (range; $5.8-7.9$ ). Whilst the mean $( \pm$ SD) left ventricular (LV) ejection fraction (EF) for patients with left ventricular systolic dysfunction was 39.23 ( \pm 6.93), (range; 15.0-49.0).

\begin{tabular}{|l|l|l|l|l|}
\hline $\begin{array}{l}\text { Echocardiographic } \\
\text { Characteristics }\end{array}$ & Min & Max & Mean & Std. Dev. \\
\hline AR $(\mathrm{cm})$ & 2.9 & 3.6 & 2.17 & 0.24 \\
\hline LA $(\mathrm{cm})$ & 2.6 & 4.5 & 3.47 & 0.66 \\
\hline IVS $(\mathrm{cm})$ & 0.7 & 1.6 & 0.90 & 0.27 \\
\hline LVPW $(\mathrm{cm})$ & 0.7 & 1.4 & 0.93 & 0.20 \\
\hline LVIDd $(\mathrm{cm})$ & 5.8 & 7.9 & 6.35 & 0.69 \\
\hline LVIDs $(\mathrm{cm})$ & 2.8 & 6.6 & 4.69 & 1.11 \\
\hline EF $(\%)$ & 15.0 & 53.0 & 35.5 & 8.1 \\
\hline E/A & 1.0 & 2.8 & 1.63 & 0.63 \\
\hline
\end{tabular}

Table 1: Echocardiographic characteristics of the patients with dilated cardiomyopathy

AR: Aortic Root; LA: Left Atrium; IVS: Interventricular Septum; LVPW: Left Ventricular Posterior Wall; LVIDd: Left Ventricular Enddiastolic dimension; LVIDs: Left Ventricular End-systolic dimension; EF: Left ventricular ejection fraction; E: Early diastolic mitral peak velocity; A: Late diastolic peak velocity

\begin{tabular}{|c|c|c|c|c|c|c|}
\hline $\begin{array}{c}\text { Echocardiographic } \\
\text { Characteristics }\end{array}$ & Yes & No & Min & Max & $\begin{array}{l}\text { Mea } \\
n\end{array}$ & $\begin{array}{l}\text { Std. } \\
\text { Dev }\end{array}$ \\
\hline$A R(\mathrm{~cm})$ & & & 2.4 & 3.9 & 3.10 & 0.32 \\
\hline $\mathrm{LA}(\mathrm{cm})$ & & & 2.3 & 4.5 & 2.93 & 0.52 \\
\hline LA dilatation & $3(8.6 \%)$ & $32(91.4 \%)$ & & & & \\
\hline IVS (cm) & & & 0.7 & 1.6 & 0.95 & 0.23 \\
\hline LVPW (cm) & & & 0.7 & 1.4 & 0.95 & 0.18 \\
\hline LVIDd (cm) & & & 3.3 & 7.9 & 4.79 & 1.09 \\
\hline LVIDs (cm) & & & 2.1 & 6.6 & 3.72 & 0.94 \\
\hline LV dilatation & $\begin{array}{l}8(22.9 \\
\%)\end{array}$ & $27(77.1 \%)$ & & & & \\
\hline $\mathrm{EF}(\%)$ & & & 15.0 & 49.0 & $\begin{array}{l}39.2 \\
3\end{array}$ & 6.93 \\
\hline FS (\%) & & & 6.0 & 24.5 & $\begin{array}{l}19.4 \\
0\end{array}$ & 4.48 \\
\hline LVSD & $\begin{array}{l}35(100 . \\
0 \%)\end{array}$ & $0(0.0 \%)$ & & & & \\
\hline$E / A$ & & & 0.8 & 2.8 & 1.35 & 0.50 \\
\hline
\end{tabular}

Table 2: Echocardiographic characteristics of the patients with left ventricular systolic dysfunction

LVSD: Left Ventricular Systolic Dysfunction; LVDD: Left Ventricular Diastolic Dysfunction 


\section{Discussion}

This study has shown high prevalence of cardiovascular abnormalities among patients attending an out-patient HIV clinic. Similar results have been demonstrated by previous studies [1-7,11]. Prevalence of cardiovascular abnormalities in HIV infection has been shown to vary widely from $28-78 \%$ [1,6,11]. A study in Lagos, Nigeria found a higher prevalence of cardiovascular abnormalities of $78 \%$ among adult HIV positive patients [1]. Even though available data show that cardiovascular abnormalities are common complications of HIV infection, it is likely that some of these patients had pre-existing cardiovascular disorders before the HIV infection.

The study has shown that pulmonary hypertension occurs with increased frequency among patients with HIV infection. Other studies have reported similar findings [23-25,29,30]. Pulmonary hypertension was the most common abnormality seen in this study. The mean RVSP of $51.5( \pm 7.8) \mathrm{mmHg}$ found in this study was similar to the mean RVSP of $68 \mathrm{mmHg}$ reported by Mesa et al. [30]. The pathogenesis of HIV-associated pulmonary hypertension is unknown. Some patients with HIV-associated pulmonary hypertension have other known risk factors for pulmonary hypertension such as intravenous drug abuse and chronic liver disease. Pellicelli at al found out that pulmonary hypertension with HIV infection seems to be related to cytokine-related stimulation and proliferation of endothelium [29]. Mesa et al also found endothelial proliferation in patients with HIV-associated pulmonary hypertension [30]. The prognosis of pulmonary hypertension in HIV disease has been shown to be poor $[25,30]$.

In this study, dilated cardiomyopathy occurred in $34 \%$ of the patients. Dilated cardiomyopathy has been found by some studies to affect $10-20 \%$ of patients with HIV infection [6,7]. A study in Yaounde, Cameroon also found prevalence of $27.5 \%$ of dilated cardiomyopathy among patients with HIV infection [12]. The pathogenesis of dilated cardiomyopathy in HIV infection is unclear. However, multiple factors have been suggested $[6,15,16,31,32]$. These include: myocarditis from direct invasion of myocardium by the HIV, co-infection with other viruses such as Coxackie virus, cytomegalovirus and Epstein-Barr virus $[6,15,16,31,32]$. Other factors are autoimmunity, cardiotoxic effects of antiretroviral drugs and selenium deficiency $[6,31,33]$. Prognosis of dilated cardiomyopathy in HIV infection has been found to be poor [6,7].

The prevalence of pericardial effusion of $23.5 \%$ seen in this study is similar to what has been reported by earlier studies [5,21]. Prendergast [5] reported a prevalence of $10-59 \%$ whilst a study in the United States of America showed a prevalence of $21 \%$ [21]. In a study in Lagos, Nigeria, pericardial effusion was seen in $47 \%$ of patients with HIV infection [1]. As shown by this study, most pericardial effusions in patients with HIV infection are small $[1,21]$ making determination of the cause of pericardial effusions difficult. Large pericardial effusions in HIV disease has been found to be strongly associated with tuberculous pericarditis [22].

Cardiac dysfunction is prevalent in HIV positive patients. This study found out that $9.5 \%$ of the HIV positive patients had left ventricular diastolic dysfunction whilst $17.5 \%$ of the patients had left ventricular systolic dysfunction. A multicentre HIV-heart study found the prevalence of left ventricular systolic dysfunction and left ventricular diastolic dysfunction among patients with HIV infection as $34.3 \%$ and $48 \%$, respectively [34]. Other studies found prevalence of left ventricular diastolic dysfunction among patients with HIV infection to range from $37-50 \%$ [35,36]. Studies done in Lagos, Nigeria and Kampala, Uganda also reported the presence of left ventricular diastolic dysfunction among patients with HIV infection [37,38].

Considering the fact that cardiovascular abnormalities influence the natural history and the prognosis of HIV infection, patients with HIV infection should be screened for the presence of cardiovascular abnormalities. Studies have shown that cardiovascular abnormalities in HIV infection are often clinically quiescent $[2,12,14,39]$, and may be attributed to disorder of other systems [14]. Echocardiography is a relevant non-invasive tool which may be used to screen for the presence of cardiovascular abnormalities in HIV positive patients. When present, early management of cardiovascular abnormalities in these patients may improve their well-being and survival. However, in resource poor countries where HIV infection has become a major public health problem, echocardiography is not available in many healthcare facilities and most of these patients do not have access to echocardiography.

\section{Conclusion}

This study has demonstrated that the prevalence of cardiovascular abnormalities among the adult HIV positive patients attending HIV clinic at KATH, Kumasi, Ghana was high. The main cardiovascular abnormalities seen were pulmonary hypertension, dilated cardiomyopathy and pericardial effusion.

\section{Acknowledgement}

The authors would like to express their sincere gratitude to the patients and staff of the HIV clinic of the Komfo Anokye Teaching Hospital, Kumasi, Ghana for their support. Without their cooperation this study would not have been done.

\section{References}

1. Olusegun-Joseph DA, Ajuluchukwu JN, Okany CC, Mbakwem AC, Oke DA, et al. (2012) Echocardiographic patterns in treatment-naïve HIVpositive patients in Lagos, south-west Nigeria. Cardiovasc J Afr 23: e1-6.

2. Nzuobontane D, Blackett KN, Kuaban C (2002) Cardiac involvement in HIV infected people in Yaounde, Cameroon. Postgrad Med J 78: 678-681.

3. Chillo P, Bakari M, Lwakatare J (2012) Echocardiographic diagnoses in HIV-infected patients presenting with cardiac symptoms at Muhimbili National Hospital in Dar es Salaam, Tanzania. Cardiovasc J Afr 23: 90-97.

4. Longo-Mbenza B, Tonduangu K, Muvova D, Phuati MB, Seghers KV, et al. (1995) [A clinical study of cardiac manifestations related to acquired immunodeficiency syndrome (AIDS) in Kinsaha]. Arch Mal Coeur Vaiss 88: 1437-1443.

5. Prendergast BD (2003) HIV and cardiovascular medicine. Heart 89: 793-800.

6. Rerkpattanapipat P, Wongpraparut N, Jacobs LE, Kotler MN (2000) Cardiac manifestations of acquired immunodeficiency syndrome. Arch Intern Med 160: 602-608.

7. Milei J, Grana D, Fernández Alonso G, Matturri L (1998) Cardiac involvement in acquired immunodeficiency syndrome--a review to push action. The Committee for the Study of Cardiac Involvement in AIDS. Clin Cardiol 21: 465-472.

8. De Castro S, Migliau G, Silvestri A, D'Amati G, Giannantoni P, et al. (1992) Heart involvement in AIDS: a prospective study during various stages of the disease. Eur Heart J 13: 1452-1459.

9. Mehta NJ, Khan IA, Mehta RN, Sepkowitz DA (2000) HIV-Related pulmonary hypertension: analytic review of 131 cases. Chest 118 : 1133-1141. 
10. Bowles NE, Kearney DL, Ni J, Perez-Atayde AR, Kline MW, et al. (1999) The detection of viral genomes by polymerase chain reaction in the myocardium of pediatric patients with advanced HIV disease. J Am Coll Cardiol 34: 857-865.

11. Barbaro G, Barbarini G, Di Lorenzo G (1996) Early impairment of systolic and diastolic function in asymptomatic HIV-positive patients: a multicenter echocardiographic and echo-Doppler study. The Gruppo Italiano Per lo Studio Cardiologico dei Pazienti Affetti da AIDS. AIDS Res Hum Retroviruses 12: 1559-1563.

12. Yunis NA, Stone VE (1998) Cardiac manifestations of HIV/AIDS: a review of disease spectrum and clinical management. J Acquir Immune Defic Syndr Hum Retrovirol 18: 145-154.

13. Niakara A, Drabo YJ, Kambire Y, Nebie LV, Kabore NJ, et al. (2002) [Cardiovascular diseases and HIV infection: study of 79 cases at the National Hospital of Ouagadougou (Burkina Faso)]. Bull Soc Pathol Exot 95: 23-26.

14. Lewis W (1989) AIDS: cardiac findings from 115 autopsies. Prog Cardiovasc Dis 32: 207-215.

15. Barbaro G (1999) Dilated cardiomyopathy in the acquired immunodeficiency syndrome. Eur Heart J 20: 629-630.

16. Barbaro G (2002). HIV-associated cardiomyopathy is not Keshan disease. J R Soc Med 95: 324.

17. Barbaro G, Fisher SD, Giancaspro G, Lipshultz SE (2001) . HIV associated cardiovascular complications: a new challenge for emergency physicians. Am J Emerg Med 19: 566-574.

18. Barbaro G, Klatt EC (2002) HIV infection and the cardiovascular system. AIDS Rev 4: 93-103.

19. Currie PF, Sutherland GR, Jacob AJ, Bell JE, Brettle RP, et al. (1995) A review of endocarditis in acquired immunodeficiency syndrome and human immunodeficiency virus infection. Eur Heart J : 15-18.

20. Frater RW (2000) Cardiac surgery and the human immunodeficiency virus. Semin Thorac Cardiovasc Surg 12: 145-147.

21. Heidenreich PA, Eisenberg MJ, Kee LL, Somelofski CA, Hollander H, et al. (1995) Pericardial effusion in AIDS. Incidence and survival. Circulation 92: 3229-3234.

22. Reuter H, Burgess LJ, Doubell AF (2005) Epidemiology of pericardial effusions at a large academic hospital in South Africa. Epidemiol Infect 133: 393-399.

23. Simonneau G, Galiè N, Rubin LJ, Langleben D, Seeger W, et al. (2004) Clinical classification of pulmonary hypertension. J Am Coll Cardiol 43: 5S-12S.

24. Mette SA, Palevsky HI, Pietra GG, Williams TM, Bruder E, et al. (1992) Primary pulmonary hypertension in association with human immunodeficiency virus infection. A possible viral etiology for some forms of hypertensive pulmonary arteriopathy. Am Rev Respir Dis 145: 1196-1200.
25. Nunes H, Humbert M, Sitbon O, et al. (2002). Declining mortality from $\mathrm{HIV}$-associated pulmonary Arterial hypertension with combined use of highly active antiretroviral therapy and long-term epoprostenol infusion. Am J Respir Crit Care Med 165: A 412.

26. Lang RM, Bierig M, Devereux RB, Flachskampf FA, Foster E, et al. (2006) Recommendations for chamber quantification. Eur J Echocardiogr 7: 79-108.

27. Devereux RB, Alonso DR, Lutas EM, Gottlieb GJ, Campo E, et al. (1986) Echocardiographic assessment of left ventricular hypertrophy: comparison to necropsy findings. Am J Cardiol 57: 450-458.

28. [No authors listed] (1998) How to diagnose diastolic heart failure. European Study Group on Diastolic Heart Failure. Eur Heart J 19: 990-1003.

29. Pellicelli AM, Barbaro G, Palmieri F, Girardi E, D'Ambrosio C, et al. (2001) Primary pulmonary hypertension in HIV patients: a systematic review. Angiology 52: 31-41.

30. Mesa RA, Edell ES, Dunn WF, Edwards WD (1998) Human immunodeficiency virus infection and pulmonary hypertension: two new cases and a review of 86 reported cases. Mayo Clin Proc 73: 37-45.

31. Ntsekhe M, Hakim J (2005) Impact of human immunodeficiency virus infection on cardiovascular disease in Africa. Circulation 112:3602-3607.

32. Barbaro G, Lorenzo G, Grisorio B, Barbarini G. (1998) Incidence of dilated cardiomyopathy and detection of HIV in myocardial cells of HIV positive patients. N Engl J Med 339: 1093-1099.

33. Currie PF, Goldman JH, Caforio AL, Jacob AJ, Baig MK, et al. (1998) Cardiac autoimmunity in HIV related heart muscle disease. Heart 79: 599-604.

34. Reinsch N, Kahlert P, Esser S, Sundermeyer A, Neuhaus K, et al. (2011) Echocardiographic findings and abnormalities in HIV-infected patients: results from a large, prospective, multicenter HIV-heart study. Am J Cardiovasc Dis 1: 176-184.

35. Mansoor A, Golub ET, Dehovitz J, Anastos K, Kaplan RC, et al. (2009) The association of HIV infection with left ventricular mass/hypertrophy. AIDS Res Hum Retroviruses 25: 475-481.

36. Nayak G, Ferguson M, Tribble DR, Porter CK, Rapena R, et al. (2009) Cardiac diastolic dysfunction is prevalent in HIV-infected patients. AIDS Patient Care STDS 23: 231-238.

37. Okoromah CA, Ojo OO, Ogunkunle OO (2012) Cardiovascular dysfunction in HIV-infected children in a sub-Saharan African country: comparative cross-sectional observational study. J Trop Pediatr 58: 3-11.

38. Lubega S, Zirembuzi GW, Lwabi P (2005) Heart disease among children with HIV/AIDS attending the paediatric infectious disease clinic at Mulago Hospital. Afr Health Sci 5: 219-226.

39. Sani MU, Okeahialam BN (2005) Epidemiology and pathogenesis of human immunodeficiency virus (HIV) related heart disease: a review. Niger J Med 14: 255-260. 